\title{
História breve da música ocidental
}

José Eduardo Martins

"Aos meus alunos, esta sintese máxima, do que disse e deixei de dizer." (José Maria Pedrosa Cardoso)

A PUbliCAÇão de livros especializados A no Brasil pode criar armadilhas para o visitante desavisado. Se o autor é do $m e ́-$ tier, tem-se, em princípio, a garantia do conhecimento da matéria. Quem escreve, a ter sob controle tema determinado, geralmente o faz com competência. Impossível não se captar sua intimidade com o roteiro traçado. Em senso inverso, todo aquele que escreve sobre área da qual desconhece fundamentos básicos, o que o levaria a ser entendido como amador ou soi disant, em determinado momento da narrativa evidencia a falha estrutural, mesmo que o discurso possa ter certa sedução. Infelizmente, a literatura sobre música de concerto, erudita ou clássica, no Brasil, tem apresentado acentuados exemplos dessas incursões não competentes, que preenchem estantes das livrarias e que se contrapõem a outras, felizmente de músicos ou musicólogos. Se os primeiros chegam a ter guarida junto a meios de comunicação não protegidos pela competência, sob aspecto outro não servem de referência, pois conceitos ou são "extraídos" de tantas obras consagradas, ou derivam de considerações arbitrárias. E todo o mal está feito. Sob outra égide, nem sempre se deve dar crédito a livros da Academia oriundos de dissertações ou teses. Quantos não são os temas escolhidos afoitamente, obedecendo à necessidade da titulação e ao inexorável prazo, que, se aprovados, convertem-se em livros? A evidência da ansiedade, tanto na seleção de temas abordados como na consecução de determinados trabalhos acadêmicos, eclode no day after, quando, a pretexto de nova tese, o que foi pesquisado é abandonado sem pudor. Temáticas tendo o Estado a subsidiá-las são preteridas em favor de outras, que servirão a novos concursos acadêmicos. E a relação íntima que deveria existir entre estudo e determinado rumo traçado na vida se esvai. E novo mal se estabelece.

A construção de uma história de área específica necessita do conhecimento insofismável e acumulado do autor. Outrora, compêndios que se debruçavam sobre segmentos do conhecimento eram escritos por um responsável. Essa missão perdurava, por vezes a envolver uma existência inteira dedicada ao mister. Hoje, equipes geralmente subvencionadas e sob coordenação "precisa" encarregam-se da extensa coleta e organização de dados. A cada especialidade, o autor designado deixa sua assinatura e a obra é edificada com certa unidade.

Abordar a história da música, utilizando como fundamento o espírito de síntese, é tarefa apenas para poucos. Essa assertiva faz entender a publicação da História breve da música ocidental, de José Maria Pedrosa Cardoso, professor da Universidade de Coimbra, como autêntico livro de síntese (Imprensa da Universidade de Coimbra, 2010). Pedrosa Cardoso tem estudos da maior relevância publicados. Se concentrações são estabelecidas em trabalhos musicológicos cerceados pelo espaço da publicação, exemplificados por 
A justificação histórica do compositor Damião de Góis (Braga, Publicações da Faculdade de Filosofia - Universidade Católica Portuguesa, 2003), ou O Réquiem e a profissão de fé de Lopes-Graça (Coimbra, Centro Acadêmico de Democracia Cristã, Nova Série n.6, 2006), há de apreender o conhecimento embasado do autor de todo um largo período histórico da música portuguesa. Ao vir a público a monumental obra $O$ canto da Paixão nos séculos XVI e XVII - A singularidade portuguesa (Imprensa da Universidade de Coimbra, 2006, 560p.), Pedrosa Cardoso estabelece bases seguras para a compreensão da música sacra em Portugal e penetra com acuidade na ourivesaria musical por meio da documentação preservada nos passionários polifônicos de Coimbra e Guimarães. Ao escrever Cerimonial da Capela Real-Um manual litúrgico de D. Maria de Portugal (1538-1577) Princesa de Parma (Coimbra, INCM - Fundação Calouste Gulbenkian, 2008, 157p.), o ilustre professor aprofunda-se em tema de difícil prospecção e revela parte do cerimonial religioso da Corte.

Em 2009 (18/4) saudara em meu blog o excelente livro de Júlio Medaglia (Música, maestro! Do canto gregoriano ao sintetizador, Globo, 2008), em que o autor, com pleno conhecimento da história da música, percorre prazerosamente os vários períodos, explicando, a partir da experiência pessoal junto a uma infinidade de partituras, os muitos meandros que levaram a arte dos sons à contemporaneidade. Em História breve da música ocidental, Pedrosa Cardoso, latinista impecável, ratifica a premissa da presente resenha ao se posicionar: "Não se pode entender e apreciar correctamente uma peça gregoriana sem conhecer o seu texto e reconhecer a funcionalidade da mesma dentro da liturgia cristã". Medaglia igualmente, no capítulo "Nasce um maestro", dá uma verdadeira aula, mercê de acúmulos de rica experiência ao longo das décadas. Afirmação que leva o leitor a confiar na competência de ambos os autores, conditio sine qua non para a referência nessa categoria de exceção, a síntese.

Quanto ao autor da História breve da música ocidental, está-se diante de um emérito conhecedor da música da cristandade, do gregoriano aos dias atuais. Pesquisador autêntico, distante das superficialidades, tendo como acréscimo o raciocínio criativo, Pedrosa Cardoso conduz o leitor, sem nenhuma empáfia, à visitação, fazendo-o viajar até a Renascença com leveza. Enfatiza a música desse período por meio de três fatores básicos: o mecenas, o compositor e os executantes, e comenta a importância da música sacra e da profana no Renascimento. Período rico na descoberta instrumental, que se expande às várias camadas sociais, e no emprego de sistemas de escrita musical que facilitariam a compreensão e divulgação da música. Em poucos termos, enquadra todo um período ibérico, foco de suas obras analítico-musicais antes citadas:

Quanto a Espanha e Portugal, a música renascentista brilhou nas capelas reais e também em quase todas as catedrais, onde se praticava uma música litúrgica de grande qualidade e também um gênero misto de popular e erudito, o vilancico, que, de algum modo, ocupou o espaço da música profana espanhola, embora em nível mais reduzido que o madrigal. Deve referir-se a Capela dos Reis Católicos (1479-1505), a Capilla Flamenca de Carlos V (1516-1556) e a Capela Real Portuguesa, que, já no tempo de D. Manuel (1495-1521), era "uma das melhores capelas de quantos reis e 


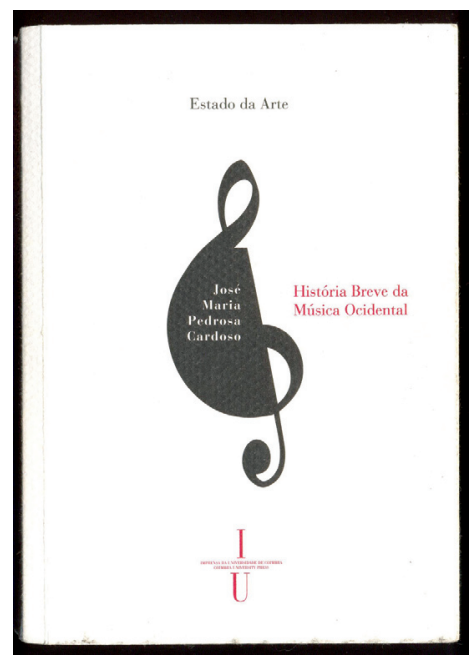

CARDOSO, José Maria Pedrosa. História breve da música ocidental. Coimbra: Imprensa da Universidade de Coimbra, 2010.

príncipes então viviam” (Damião de Góis).

Portugal e Espanha mostrariam em seu histórico musical influências mútuas, tantas oriundas da longa ocupação árabe.

Divide-se o livro em quatro capítulos e inúmeros subcapítulos, tendo o som como epicentro: "O som místico da época medieval", "O som humano da época moderna", "O som livre da época contemporânea" e, o mais longo, "O som plural da época atual”. Nesses breves capítulos, Pedrosa Cardoso caminha com o leitor, ilustrando-o, sem ser enfático. As 159 páginas da História breve da música ocidental têm pois o mérito da síntese. Não se trata de um resumo, mas de sementes fecundas plantadas, pois esses capítulos fornecem farto material - no caso, multum in minimo - destilado de maneira sequencial, sem quaisquer rupturas. Pequenos textos que podem propiciar ao leitor olhares outros, convite ao aprofundamento. Se as tantas histórias da música, das caudalosas às mais concentradas, percorrem os períodos, muitas delas a evidenciar o conhecimento maior ou menor dos autores, não poucas vezes tem-se o conteúdo doutoral. Tornam-se referência, mas dificilmente o leigo poderá compreendê-las.

Se do barroco, passando-se pelo classicismo e pelo período romântico - que na realidade, conforme posição que defendo desde os anos 1980, não tem interrupção do início do século XIX a meados do século XX, mas sim vertentes diferenciadas, mas românticas sempre, sem prefixos agregadores, pois -, ao século XX, naquilo que Pedrosa bem define em subcapítulo como "pluralismo cultural", seria todavia a música do último cento que atrai um olhar ainda mais pormenorizado do autor. Dir-se-ia que as múltiplas tendências surgidas após a desagregação da tonalidade fascinam Pedrosa Cardoso, pelo multidirecionamento a envolver técnicas composicionais, convivência do erudito com o popular, tecnologia, sintetizador, o concerto democratizado a abrigar em fronteiras distintas todas as correntes e, paradoxalmente, em situações de congraçamento, sob um mesmo teto. E como fonte viva e até "independente", a presença da música de raiz, o folclorismo que pulsa e que teria um olhar diferenciado sobre a sua autêntica manifestação, mais acentuadamente a partir da segunda metade do século XIX.

$\mathrm{O}$ fato de a música até o século XX ter sido extremamente ventilada em infindáveis compêndios propiciaria a $\mathrm{Pe}$ drosa Cardoso - mera suposição - um debruçamento maior em personalidades da criação musical, sobretudo da segunda metade do século XX, não se alongando sobre determinadas figuras basilares dos séculos precedentes. Entende, contudo, 
ter sido Debussy "o grande nome da charneira dos séculos XIX-XX, tal como Monteverdi foi para os séculos XVI-XVII e Beethoven para os séculos XVIII-XIX”. Agregaria, no decurso da história, Schönberg.

A facilidade com que os vários temas são tratados por Pedrosa Cardoso, assim como a sua capacidade para tornar segmentos complexos ou controvertidos da história da música palatáveis ao estudante e ao leigo já bastariam para a recomendação da obra. Uma pequena observação apenas, que deveria ser entendida como um desafio. Teria faltado no significativo livro capítulo reservado à música em Portugal. Aguarda-se sempre a sua inserção definitiva nos repertórios internacionais. Nesse cenário global irreversível, em que a música se coloca como uma das mais importantes fontes do pensar humano, urge o esforço coletivo nesse desiderato de divulgação mais ampla, interna e externamente, da música criada em terras lusíadas. E Pedrosa Cardoso tem-se mostrado, por meio de obras anteriores, um grande defensor da música portuguesa. Quem sabe não dedique a sua pena a uma próxima História breve da música em Portugal?

Instigante a frase final de História breve da música ocidental: "Não se sabe como será a música do futuro. Talvez esta ignorância, humildemente assumida, explique o mistério do som, que mudará, ou não, à justa medida do ser humano".

José Eduardo Martins é pianista e professor aposentado da Universidade de São Paulo.@-martins.je@terra.com.br www.joseeduardomartins.com 